\title{
Color Stability and Aging of Plastic Veneering Materials
}

J. M. POWERS* and P. L. FAN

School of Dentistry, The University of Michigan, Ann Arbor, Michigan 48109

The color stability and aging characteristics of commercial plastic veneering materials were studied in vitro by an accelerated aging method. The veneering materials were similar in color to, but more opaque than, composite restorative materials. Changes in color during aging were minimal. Weight loss occurred during aging.

\section{J Dent Res 60(9):1692-1696, September 1981}

\section{Introduction.}

Physical and mechanical properties of plastics for veneering of cast gold restorations have been reported. ${ }^{1-3}$ Typical crown and bridge plastics have been formulated from methyl methacrylate or triethylene glycol dimethacrylate monomer and poly (methyl methacrylate) polymer, and have had low inorganic content (less than $2 \%$ ). ${ }^{3}$ Recently, a composite resin with $24.6 \%$ inorganic filler ${ }^{3}$ was introduced as a veneering material.

An important property of a plastic veneering material is color stability. ${ }^{1,2}$ An in vitro method of evaluation of color stability by accelerated aging has been utilized for restorative resins..$^{4,5}$ Dennison et al. ${ }^{6}$ have shown that changes in color observed clinically in a 24-month in vivo study of class 4 composite restorations correlated well with these in vitro data. Accelerated aging of composites has also resulted in surface degradation of samples and may be a useful model for evaluation of chemical durability or aging of resins. ${ }^{7}$

The purpose of this research was to evaluate the color stability and aging characteristics of commercial plastic veneering materials in vitro by an accelerated aging method.

Received for publication November 26, 1980 Accepted for publication January 28, 1981 The cooperation of L.D. Caulk Co. and H.D. Justi Co. for providing commercial materials is acknowledged.

Dr. Fan's address is: Council on Dental Materials, Instruments and Equipment, American Dental Association, Chicago, IL 60611.

*Address for reprints: Dr. Powers

\section{Materials and methods.}

The color and aging characteristics of five commercial plastic veneering materials were evaluated under conditions of accelerated aging. The code, shade, batch numbers, and manufacturer of each material studied are listed in Table 1.

Three disks ( $36 \mathrm{~mm}$ diameter and $1.3 \mathrm{~mm}$ thickness) for evaluation of color and five samples (about $20 \times 20 \mathrm{~mm}$ square and $1 \mathrm{~mm}$ thick) for evaluation of aging characteristics were prepared for each material by polymerization in appropriate dies according to manufacturers' instructions. After preparation, the samples were stored in an oven at $37^{\circ} \mathrm{C}$ for $24 \mathrm{~h}$. The color samples were evaluated for color at baseline. The aging samples were dried to a constant weight over freshly regenerated silica gel in a desiccator. The balance* was accurate to $0.1 \mathrm{mg}$.

All samples were exposed to conditions of accelerated aging for a total of $900 \mathrm{~h}$ in a weathering chamber ${ }^{\dagger}$ at $43^{\circ} \mathrm{C}$ and $90 \%$ relative humidity. One surface of each sample was subjected continuously to the radiation of a 2500 watt ultraviolet (uv)

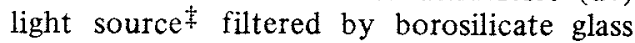
and to an intermittent water spray for 18 min every two $h$. The intensity of the uv radiation was measured with a uv meter $\S$ to be about $11.2 \mathrm{mWatts} / \mathrm{cm}^{2}$ at the specimen position.

Curves of percent reflectance versus wavelength $(\lambda)$ were obtained for each color sample between 405 and $700 \mathrm{~nm}$ with a double-beam, ultraviolet-visible spectrophotometer ${ }^{\infty}$ and integrating sphere. 9 Lumin-

*Model H 14, Mettler Instrument Corp., Princeton, NJ 08540

tWeather-Ometer 25WR, Atlas Electric Devices Co., Chicago, IL 60613

$\$ 12-2881$ Xenon Burner, Atlas Electric Devices Co., Chicago, IL 60613

$\S$ Model J-221, Ultraviolet Products, Inc., San Gabriel, CA 91778 
ous reflectance (Y), dominant wavelength (DW), and excitation purity (EP) were obtained for each sample backed by both a black $^{* *}$ and a white standard $\dagger^{\dagger} 8$ An estimate of the opacity of each material was obtained by calculation of the contrast ratio (CR), $Y_{\text {black standard }} / Y_{\text {white standard }}{ }^{9}$ Color evaluations were made before weathering (baseline) and after exposure of 300,600 , and $900 \mathrm{~h}$.

After $900 \mathrm{~h}$, the aging samples were again dried to constant weight. The change in weight caused by aging was calculated and used to determine volume loss. Density was determined on one new sample of each material by a water displacement technique. The exposed surface area $\left(\mathrm{mm}^{2}\right)$ of a sample was measured to be 520 for $\mathrm{BL}$, 530 for BT, 540 for IS, 500 for $\mathrm{PP}$, and 480 for TJ. Surface morphology of the materials was observed after $900 \mathrm{~h}$ of aging by scanning electron microscopy. \#

The spectrophotometric parameters ( $Y$, $D W, E P$, and $C R$ ) and aging parameters were studied by analysis of variance ${ }^{10}$ to determine the effects of aging. Scheffe intervals ${ }^{11}$

${ }^{\infty}$ ACTA C III UV-visible Spectrophotometer, Beckman Instruments, Inc., Irvine, CA 92664

ASPH-U Integrating Sphere, Beckman Instruments, Inc., Irvine, CA 92664

**Part No. 375287, Beckman Instruments, Inc., Irvine, CA 92664

t†Part No. 375285, Beckman Instruments, Inc., Irvine, CA 92664

\#JSM-US, Japan Electron Optics Laboratory, Japan at the $95 \%$ level of confidence were calculated for comparisons among means.

\section{Results.}

Mean values and standard deviations of luminous reflectance (Y), dominant wavelength (DW), excitation purity (EP), and contrast ratio (CR) are listed in Table 2 for the plastic veneering materials at baseline. Changes in these parameters at each evaluation period are listed there also. These changes were computed by subtracting the value of the parameter at 300,600 , and $900 \mathrm{~h}$ from the baseline value. Values of Scheffe intervals computed from analysis of variance were $Y, 1.2 ; D W, 0.15 \mathrm{~nm}$; $\mathrm{EP}, 0.007$; and $\mathrm{CR}, 0.004$ for comparisons among times at the $95 \%$ level of confidence.

Values of luminous reflectance $(\mathrm{Y})$ decreased for IS between zero and $300 \mathrm{~h}$ and for PP between zero and $600 \mathrm{~h}$. Subsequent changes in $\mathrm{Y}$ for IS and $\mathrm{PP}$, as well as changes in $\mathrm{Y}$ for $\mathrm{BL}, \mathrm{BT}$, and $\mathrm{TJ}$ between zero and $900 \mathrm{~h}$, were not statistically significant.

Values of dominant wavelength (DW) decreased for $\mathrm{BL}, \mathrm{BT}$, and $\mathrm{PP}$, increased for IS, but did not change significantly for $\mathrm{TJ}$ between zero and $300 \mathrm{~h}$ of aging. Further aging caused changes in DW for BL, BT, and $\mathrm{PP}$, but not for IS or TJ.

Values of excitation purity (EP) decreased for IS and TJ, but did not change significantly for $\mathrm{BL}$ and $\mathrm{BT}$ between zero and $300 \mathrm{~h}$ of aging. Further aging resulted in increases in EP for $\mathrm{BL}$ and $\mathrm{BT}$, but no significant changes in IS or TJ compared to $\mathrm{EP}$ at $300 \mathrm{~h}$. The values of excitation purity

TABLE 1

CODE, NAME, BATCH NUMBERS, AND MANUFACTURER OF PRODUCTS TESTED

\begin{tabular}{|c|c|c|c|c|}
\hline$\overline{\text { Code }}$ & Product Name (Shade) & Batch & Numbers & Manufacturer \\
\hline $\mathrm{BL}$ & Biolon $(B-62)$ & $\begin{array}{l}\text { powder } \\
\text { liquid }\end{array}$ & $\begin{array}{l}-110278 \\
-\quad 021379\end{array}$ & $\begin{array}{l}\text { L.D. Caulk Co. } \\
\text { Milford, DE }\end{array}$ \\
\hline BT & Biotone (G 2) & $\begin{array}{l}\text { powder } \\
\text { liquid }\end{array}$ & $\begin{array}{l}-012579 \\
-\quad 041878\end{array}$ & $\begin{array}{l}\text { L.D. Caulk Co. } \\
\text { Milford, DE }\end{array}$ \\
\hline IS & Isosit (D-4A) & $\begin{array}{l}\text { base } \\
\text { catalyst }\end{array}$ & $\begin{array}{l}367 \mathrm{~S} \\
432 \mathrm{~S}\end{array}$ & $\begin{array}{l}\text { Degussa Corp. } \\
\text { Teterboro, NJ }\end{array}$ \\
\hline $\mathrm{PP}$ & Pyroplast (62) & $\begin{array}{l}\text { powder } \\
\text { liquid }\end{array}$ & $\begin{array}{l}7276 \\
8232\end{array}$ & $\begin{array}{l}\text { H.D. Justi Co. } \\
\text { Philadelphia, PA }\end{array}$ \\
\hline T J & Thermojel (62) & $\begin{array}{l}\text { powder } \\
\text { liquid }\end{array}$ & $\begin{array}{l}-\quad 102778 \\
-\quad 020179\end{array}$ & $\begin{array}{l}\text { L.D. Caulk Co. } \\
\text { Milford, DE }\end{array}$ \\
\hline
\end{tabular}


TABLE 2

SPECTROPHOTOMETRIC COLOR DATA AT BASELINE AND CHANGES IN COLOR AFTER AGING FOR PLASTIC VENEERING MATERIALS OBTAINED WITH A WHITE BACKGROUND

\begin{tabular}{lcccccc} 
& & & & \multicolumn{3}{c}{ Change in Parameter Compared to Baseline } \\
Code & Property & Baseline Value & $300 \mathrm{~h}$ & $600 \mathrm{~h}$ & $900 \mathrm{~h}$ \\
\hline BL & Y & $64.0(0.3$ & $*$ & -0.9 & -0.4 & -0.3 \\
& DW, nm & $578.56(0.05)$ & -0.50 & -0.30 & -0.30 \\
& EP & $0.259(0.004)$ & 0.005 & 0.015 & 0.017 \\
& CR & $0.701(0.012)$ & 0.002 & -0.008 & -0.013 \\
\hline BT & Y & $62.6(0.3)$ & -0.8 & -0.7 & -0.4 \\
& DW, nm & $579.88(0.13)$ & -0.44 & -0.17 & -0.18 \\
& EP & $0.294(0.006)$ & 0.003 & 0.014 & 0.016 \\
& CR & $0.728(0.010)$ & 0.010 & -0.006 & -0.009 \\
\hline IS & Y & $56.0(1.4)$ & -4.8 & -6.0 & -5.9 \\
& DW, nm & $579.92(0.05)$ & 0.40 & 0.48 & 0.52 \\
& EP & $0.262(0.006)$ & -0.043 & -0.050 & -0.050 \\
& CR & $0.823(0.011)$ & 0.011 & 0.018 & 0.016 \\
\hline PP & Y & $63.4(1.2)$ & -0.5 & -2.1 & -2.0 \\
& DW, nm & $577.39(0.08)$ & -0.37 & 0.27 & 0.19 \\
& EP & $0.314(0.007)$ & -0.007 & 0.004 & 0.006 \\
& CR & $0.672(0.012)$ & 0.001 & -0.005 & -0.015 \\
\hline TJ & Y & $64.4(2.7)$ & 0.1 & -1.1 & -0.8 \\
& DW, nm & $578.13(0.14)$ & 0.01 & -0.13 & -0.14 \\
& EP & $0.280(0.008)$ & -0.023 & -0.022 & -0.016 \\
& $\mathrm{CR}$ & $0.746(0.019)$ & 0.023 & 0.019 & 0.016 \\
\hline
\end{tabular}

* Mean of three replications with standard deviations in parentheses.

$\dagger$ Change equals the value at the specific times minus the value at baseline.

of $\mathrm{PP}$ at 300,600 , and $900 \mathrm{~h}$ were not significantly different from those at baseline.

Values of the contrast ratio increased for BT, IS, and TJ, but did not change significantly for BL or PP after $300 \mathrm{~h}$ of aging. Further aging resulted in decreased values of $\mathrm{CR}$ for $\mathrm{BL}, \mathrm{BT}$, and $\mathrm{PP}$ and increased values of CR for IS compared to baseline. Further aging of $T J$ resulted in values of $E P$ that were greater than those at baseline, but less than the 300-hour values.

Parameters describing the aging of the plastic veneering materials are listed in Table 3. Weight loss after $900 \mathrm{~h}$ of aging ranged from $0.15 \mathrm{mg} / \mathrm{gm}^{2}$ for $\mathrm{BL}$ to $0.66 \mathrm{mg} / \mathrm{cm}^{2}$ for BT. Volume loss was determined from the data of weight loss, density, and surface area. It ranged from $1.3 \times 10^{-3} \mathrm{~mm}^{3} / \mathrm{mm}^{2}$ for $\mathrm{BL}$ to $5.6 \times 10^{-3} \mathrm{~mm}^{3} / \mathrm{mm}^{2}$ for BT. Values of the Scheffe interval at the $95 \%$ level of confidence were $0.14 \mathrm{mg} / \mathrm{cm}^{2}$ and $1.2 \times 10^{-3} \mathrm{~mm}^{3} / \mathrm{mm}^{2}$, respectively. A scanning electron photomicrograph of the surface of IS after $900 \mathrm{~h}$ of aging is shown in the Fig. The surfaces of the other materials before and after aging, as well as IS before aging, were without distinctive morphology.

\section{Discussion.}

The baseline colors of the plastic veneering materials fall within the ranges of luminous reflectance, dominant wavelength, and excitation purity observed for typical shades of 13 composite restorative materials as shown in Table 4.5,12 Values of the contrast ratio of the veneering materials, however, tend to be higher than those of the composites. This increased opacity of the veneering materials may serve to mask the less desirable color of the metal substructure of the crown and bridge restoration. The effect of thickness of the veneering material on color and opacity should be studied further.

Changes in the spectrophotometric parameters of color of the plastic veneering materials were observed as a result of accelerated aging. Material IS showed changes comparable with those observed for microfilled composites, ${ }^{5}$ whereas the other facing materials showed many fewer changes. Research on color of denture resins has demonstrated that changes in spectrophotometric parameters of 1.1 units in 
TABLE 3

PARAMETERS DESCRIBING AGING OF PLASTIC VENEERING MATERIALS WITH COMPARISONS WITH OTHER RESTORATIVE PLASTICS

\begin{tabular}{lccc}
\hline \hline & $\begin{array}{c}\text { Weight Loss/ } \\
\text { Surface Area, } \\
\mathrm{mg} / \mathrm{cm}^{2}\end{array}$ & Density, g/cm ${ }^{3}$ & $\begin{array}{c}\text { Volume Loss/ } \\
\text { Surface Area, } \\
10^{-3} \mathrm{~mm}^{3} / \mathrm{mm}^{2}\end{array}$ \\
\hline BL & $0.15(0.04)^{*}$ & 1.233 & $1.3(0.3)$ \\
BT & $0.66(0.32)$ & 1.177 & $5.6(2.6)$ \\
IS & $0.35(0.09)$ & 1.278 & $2.7(0.7)$ \\
PP & $0.20(0.09)$ & 1.052 & $1.8(0.9)$ \\
TJ & $0.44(0.04)$ & 1.107 & $3.9(0.2)$ \\
Sealant 7 & 0.46 & 1.188 & 3.9 \\
$\begin{array}{l}\text { Microfilled Composites } \\
\text { (two products) }\end{array}$ & $0.28-0.51$ & $1.392-1.462$ & $2.0-3.5$ \\
Conventional Composites & & & $3.6-5.9$ \\
(four products) $^{7}$ & $0.46-1.16$ & $1.960-2.098$ & \\
\hline
\end{tabular}

*Mean values of five replications with standard deviations in parentheses.

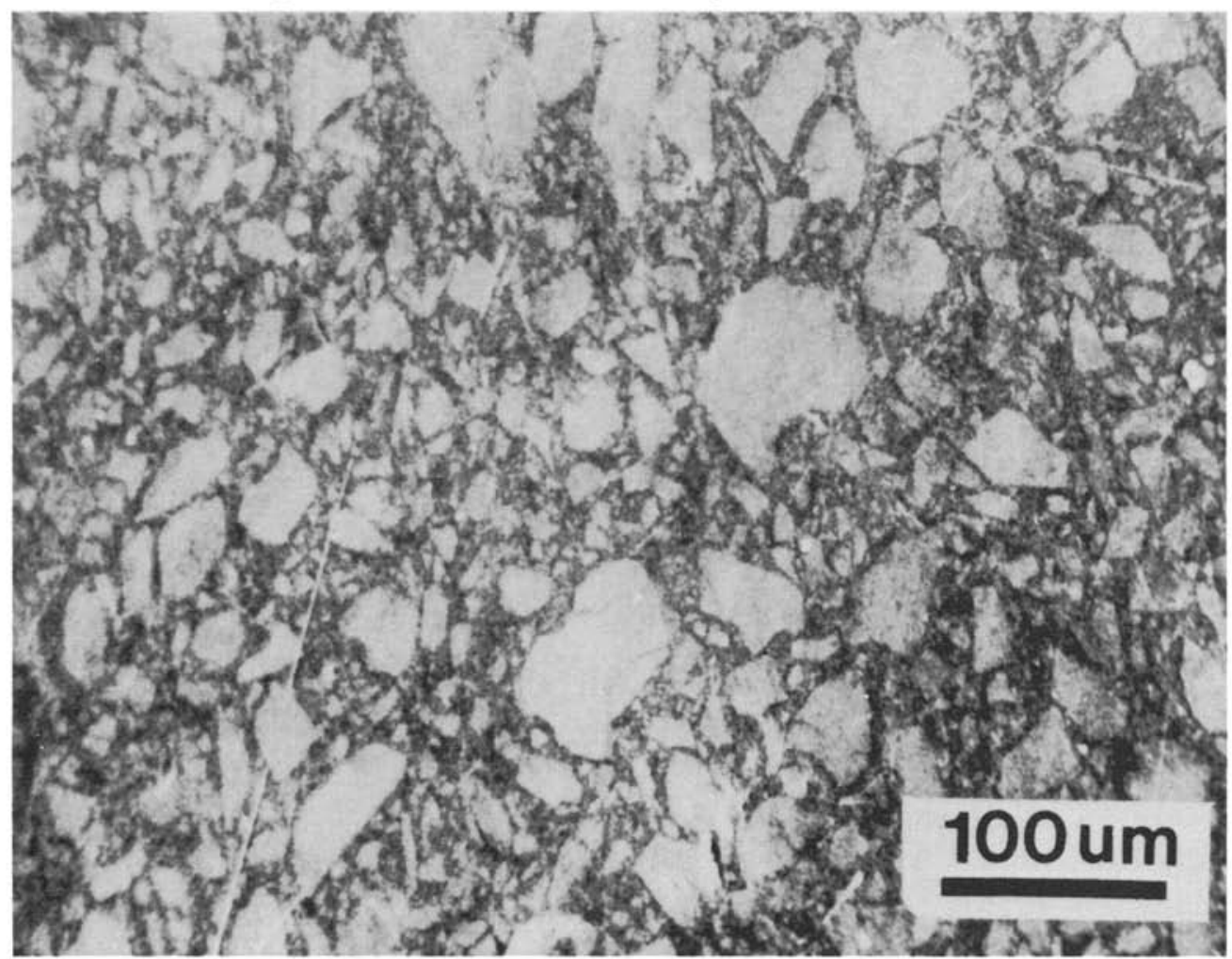

Fig. - Scanning electron photomicrograph of surface of IS after $900 \mathrm{~h}$ of accelerated aging.

luminous reflectance, 0.012 units in excitation purity, and $2.2 \mathrm{~nm}$ in dominant wavelength can be detected visually by a trained observer. ${ }^{13}$ The changes observed instrumentally for $\mathrm{BL}, \mathrm{BT}$, IS, PP, and TJ as a result of accelerated aging were very difficult to detect visually.
The plastic veneering materials lost weight as a result of aging for $900 \mathrm{~h}$. With the exception of BT, the ranges of weight loss and volume loss were more similar to those ranges observed for microfilled composites than for those of conventional composites or a sealant as shown in Table 3 . The 
TABLE 4

COMPARISON OF COLOR DATA AT BASELINE FOR PLASTIC VENEERING MATERIALS AND COMPOSITE RESTORATIVE MATERIALS

\begin{tabular}{lcccc}
\hline & \multicolumn{4}{c}{ Spectrophotometric Parameter* } \\
\cline { 2 - 5 } & $\mathrm{Y}$ & $\mathrm{DW}, \mathrm{nm}$ & $\mathrm{EP}$ & $\mathrm{CR}$ \\
\hline $\begin{array}{l}\text { Plastic Veneering } \\
\text { Materials (five products) }\end{array}$ & $56.0-64.4$ & $577.39-579.92$ & $0.259-0.314$ & $0.672-0.823$ \\
$\begin{array}{c}\text { Composites } \\
(13 \text { products) }\end{array} 5,12$ & $51.6-78.9$ & $573.72-579.57$ & $0.160-0.355$ & $0.559-0.742$ \\
\hline
\end{tabular}

*Data obtained with a white background.

solubility of restorative resins in water for $14 \mathrm{~d}$ has been reported to range from less than 0.01 to $0.19 \mathrm{mg} / \mathrm{cm}^{2}$ for composites and $0.23 \mathrm{mg} / \mathrm{cm}^{2}$ for an unfilled acrylic. ${ }^{14}$ Although the plastic veneering materials were exposed directly to water spray for only $5.6 \mathrm{~d}$ during aging for $900 \mathrm{~h}$, their weight loss is comparable to or greater than the sc.ubility of an unfilled acrylic. The weight loss associated with the veneering materials as a result of in vitro aging apparently is more complex than solubility and may involve chemical degradation.

\section{Conclusions.}

The color stability and aging characteristics of commercial plastic veneering materials were studied in vitro by an accelerated aging method. Values of luminous reflectance, dominant wavelength, and excitation purity at baseline were similar to values reported for composite restorative materials. The veneering materials were more opaque than composites. After aging for $900 \mathrm{~h}$, small changes in color were observed instrumentally, but were difficult to detect visually. Weight loss of some of the veneering materials after aging was greater than that anticipated from solubility in water alone.

\section{REFERENCES}

1. PEYTON, F.A. and CRAIG, R.G.: Current Evaluation of Plastic Crown and Bridge Prosthesis, J Prosthet Dent 13:743-753, 1963.

2. McCUNE, RJ.; PHILLIPS, R.W.; and SWARTZ, M.L.: An Evaluation of a New Resin Veneering Material, South CA Dent Assoc $J$ $36: 496-498,1968$.
3. POWERS, J.M.; FAN, P.L.; DOOTZ, E.R.; and LITVIN-SCHRAMM, S.B.: Properties of Plastic Facing Materials, MI Dent Assoc J, In press.

4. POWERS, J.M.; DENNISON, J.B.; and KORAN, A.: Color Stability of Restorative Resins under Accelerated Aging, $J$ Dent Res 57:964-970, 1978.

5. POWERS, J.M.; FAN, P.L.; and RAPTIS, C.N.: Color Stability of New Composite Restorative Materials under Accelerated Aging, $J$ Dent Res 59:2071-2074, 1980.

6. DENNISON, J.B.; CRAIG, R.G.; and BOZELL, R.R.: Clinical Evaluation of Class 4 Restorations for Color Stability, IADR Progr \& Abst 58: No. 328, 1979.

7. POWERS, J.M.; FAN, P.L.; and MARCOTTE, M.: In vitro Accelerated Aging of Composites and a Sealant, $J$ Dent Res, In press.

8. WYSZECKI, G. and STILES, W.S.: Color Science, New York: Wiley \& Sons, Inc., 1967, $628 \mathrm{p}$.

9. Opacity of Paper, D589-65 (1970), In: ASTM Standards, Part 20, Philadelphia: American Society for Testing and Materials, 1975, pp. 86-88.

10. DALBY, J.: BMD8V - Analysis of Variance, Ann Arbor: Statistical Research Laboratory, University of Michigan, 1968, $4 \mathrm{p}$.

11. GUENTHER, W.C.: Analysis of Variance, Englewood Cliffs, NJ: Prentice-Hall, 1964, $199 \mathrm{p}$.

12. DENNISON, J.B.; POWERS, J.M.; and KORAN, A.: Color of Dental Restorative Resins, J Dent Res 57:557-562, 1978.

13. POWERS, J.M. and LEPEAK, P.J.: Parameters that Affect the Color of Denture Resins, $J$ Dent Res 56:1331-1335, 1977.

14. DENNISON, J.B. and CRAIG, R.G.: Physical Properties and Finished Surface Texture of Composite Restorative Resins, JADA 85: 101-108, 1972 . 